\title{
RESISTÊNCIA GENÉTICA À PODRIDÃO AMARGA EM MAÇÃS, DETERMINADA PELA TAXA DE DESENVOLVIMENTO DA DOENÇA EM FRUTOS COM E SEM FERIMENTOS ${ }^{1}$
}

\author{
FREDERICO DENARDI², ONOFRE BERTON³, MÁRCIA MONDARDO SPENGLER ${ }^{4}$
}

\begin{abstract}
Resumo - A maçã é um dos mais importantes produtos agrícolas de Santa Catarina e a segunda mais importante fruteira de clima temperado do Brasil. No entanto, a produção brasileira está alicerçada em cultivares importadas suscetíveis a diversas doenças. A podridão amarga causada pelo fungo Glomerella cingulata (Stoneman) Spaulding \& Schrenk, (forma imperfeita Colletotrichum gloeosporioides (Penz.) Sacc.) é uma das mais importantes doenças de verão, podendo causar perdas muito elevadas. No presente trabalho, a inoculação artificial de $C$. gloesporioides em frutos com e sem ferimentos objetivou verificar a diferença de evolução da podridão amarga e identificar possíveis fontes de resistência nas seleções e novas cultivares de macieira desenvolvidas pela Epagri. Verificou-se ampla variação na reação de resistência entre as cultivares e seleções estudadas. O estabelecimento e o desenvolvimento da podridão amarga mostrou-se muito mais rápido através de ferimentos. As seleções M-6/00 e M-13/00 manifestaram resistência superior à das atuais cultivares Gala, Fuji e Golden Delicious. Essas seleções também apresentaram resistência superior à cv. Melrose, indicada como resistente em outros estudos.
\end{abstract}

Termos para indexação: Macieira, podridão amarga, resistência genética

\section{GENETIC RESISTANCE TO BITTER ROT ON APPLES DETERMINED BY THE DEVELOPMENT RATE OF THE DISEASE ON FRUITS WITH AND WITHOUT WOUNDS}

\begin{abstract}
Apple is one of the most important agricultural product of Santa Catarina State and represents the second most important temperate-zone fruit in Brazil. However the production is based on imported cultivars susceptible to many fungal diseases. Bitter rot caused by the fungus Glomerella cingulata (Stoneman) Spaulding \& Schrenk, (amorphous = Colletotrichum gloeosporioides (Penz.) Sacc.), is one of the most important summer diseases of apple in southern Brazil. Severe damages may occur every year. In the present study, artificial inoculation of $C$. gloeosporioides on fruits with and without wounding was carried out to verify differences in the evolution of bitter rot and to identify sources of resistance to the disease among the new apple cultivars and selections of the Epagri breeding program. The establishment and the development of bitter rot on apple fruits were faster through wounds. The selections $M-6 / 00$ and $M-13 / 00$ showed higher level of resistance to bitter rot than the cultivars Gala, Fuji and Golden Delicious. These apple selections expressed an even higher level of resistance to this disease than cv. Melrose, indicated as resistant in previous studies.
\end{abstract}

Index terms: Apple, bitter rot, genetic resistance

\section{INTRODUÇÃO}

A maçã é a segunda mais importante fruta de clima temperado no Brasil, com produção de 857.340 t em 2002, sendo Santa Catarina o principal Estado produtor, com 55,3\% da produção nacional.

Concentrada na Região Sul do Brasil, onde as temperaturas e o regime de chuvas são elevados durante o verão, favorecendo o desenvolvimento de doenças (BLEICHER et al., 1986; BONETI et al., 1999), cerca de $95 \%$ da produção provém das cultivares Gala e Fuji, ambas muito suscetíveis à podridão amarga (CAMILO, 1989).

As pesquisas em melhoramento genético da macieira na Epagri têm conseguido avanços significativos no desenvolvimento de cultivares e seleções resistentes a importantes doenças como a sarna (Venturia inaequalis) e a mancha foliar de Glomerella $(C$. gloeosporioides) nos últimos anos. A incorporação de resistência simultânea a estas duas doenças e à podridão amarga, principais doenças da macieira no sul do Brasil, poderá reduzir o uso de fungicidas em mais de $80 \%$. Isto terá efeitos imediatos, não apenas na redução dos custos de produção, mas também na proteção do produtor, na saúde do consumidor e na preservação do meio ambiente.

As perdas de produção de maçãs no sul do Brasil, causadas somente pelo ataque de podridão amarga, podem chegar a $50 \%$ (Bleicher, 1980). No entanto, segundo Dunegan (1953), as perdas pelo ataque desta doença no Estado de Arkansas, EUA chegaram a 96\% da produção.

Muito embora pareça não existir imunidade genética à podridão amarga (Anderson, 1920), têm sido observadas diferenças na reação de resistência entre as cultivares já testadas (Dunegan, 1953; Singh \&
Chand, 1969; Camilo, 1989). Dunegan (1953) observou que, dentre outras cultivares, a Golden Delicious é mais suscetível que a Delicious, as duas mais importantes cultivares existentes no mercado. Camilo (1989) constatou um amplo gradiente de resistência genética entre os genótipos testados. As cultivares Gala, Fuji e Golden Delicious revelaram-se susceptíveis. Por outro lado, as cultivares Red Rome e Melrose mostraram possuir bom nível de resistência. Elevado grau de resistência genética em sub-espécies de macieira silvestre também tem sido reportado (Camilo, 1989). Estas sub-espécies, no entanto, produzem frutos de tamanho muito pequeno. Sendo este um fator geneticamente dominante, os ganhos genéticos em termos de tamanho são muito lentos. O desenvolvimento de cultivares resistentes a partir deste tipo de germoplasma levaria várias gerações para se atingir tamanho comercial. Por isso, a busca de resistência genética dentre os materiais que já produzem frutos de tamanho comercial é a alternativa mais indicada, levando em conta o tempo e os recursos financeiros necessários ao desenvolvimento da pesquisa.

Embora G. cingulata possa atacar frutos intactos (Kaul \& Munjal, 1981), a agressividade parece ser maior e a evolução da doença mais rápida em frutos com ferimentos (Clinton, 1902; Schrenk \& Spaulding., 1903). A rapidez da evolução dos sintomas está diretamente relacionada às condições de temperatura e umidade relativa do ar (Anderson, 1920). Por outro lado, a severidade da doença também depende do estádio de desenvolvimento do fruto. Frutos no ponto de consumo parecem ser mais suscetíveis (Roberts \& Pierce, 1918). A severidade da doença também depende diretamente da concentração do inóculo no momento da infecção (Camilo, 1989), porém, é variável

\footnotetext{
(Trabalho $n^{\circ}$ 073/2003). Recebido: 14/03/2003. Aceito para publicação: 13/11/2003.

${ }^{2}$ Eng. Agr. M.Sc. Fruticultura de Clima Temperado, UFPEL, Pesquisador em Melhoramento Genético Vegetal, Est. Exp. Caçador-EPAGRI,-CEP 89500-000, C.P.591, Caçador, SC. E-mail: denardi@epagri.rct-sc.br.

${ }^{3}$ Eng. Agr. PhD Fitopatologia - Cornell University, USA, Pesquisador em Fitopatologia, Est. Exp. Caçador-EPAGRI, CEP 89500-000, C.P. 591, Caçador, SC. Email: berton@epagri.rct-sc.br.

${ }^{4}$ Eng.(a) Agr.(a) M.Sc Estatística e Experimentação Agronômica, USP, Pesquisadora em Estatística e Experimentação Agronômica, Est. Exp. Caçador-EPAGRI, CEP 89500-000, C.P. 591, Caçador, SC. E-mail: mmondardo@epagri.rct-sc.br
} 
entre as diferentes cultivares (Clinton, 1902; Schrenk \& Spaulding., 1903).

\section{MATERIAISE MÉTODOS}

Este estudo foi realizado na Estação Experimental de Caçador/ Epagri, em Santa Catarina, localizada a $960 \mathrm{~m}$ de altitude, onde a precipitação pluviométrica anual é de $1.700 \mathrm{~mm}$. A precipitação durante o período verão/outono varia de $182 \mathrm{~mm}$ em janeiro a $134 \mathrm{~mm}$ em março. As temperaturas médias durante este período variam de $20,7^{\circ} \mathrm{C}$ em janeiro a $19,4^{\circ} \mathrm{C}$ em março, caracterizando condições favoráveis ao desenvolvimento de doenças de verão como a podridão amarga. Foram testados os seguintes genótipos de macieira: cultivares Golden Delicious, Melrose, Gala, Fuji, Condessa, Imperatriz, Fred Hough, Baronesa, Daiane e as seleções locais M-6/00, M-11/00, M-12/00 e M$13 / 00$.

Os testes foram realizados durante os meses de abril e maio de 2002, utilizando-se frutos maduros dos genótipos acima. O delineamento experimental foi inteiramente casualisado, com 3 repetições de 5 frutos cada para os tratamentos com e sem ferimentos. Os frutos foram divididos em parcelas compostas pelos genótipos, e sub-parcelas compostas de frutos com e sem ferimentos. Precedendo a inoculação, os frutos foram lavados com água destilada, secados, desinfetados com hipoclorito de sódio $(\mathrm{NaOCl})$ a $0,5 \%$, lavados novamente com água destilada e colocados para secar sobre papel toalha.

O inóculo foi obtido a partir de um isolado de Colletotrichum gloeosporioides proveniente de frutos da cultivar Fuji com o sintoma típico de podridão amarga, coletados em Caçador, SC. O isolado foi produzido em cultura pura em placas de petri, contendo BDA, mantidas em câmara de crescimento BOD, sob regime de luz de $12 \mathrm{~h}$ por 14 dias. Os conídios foram removidos das placas por raspagem, usando água esterilizada. A concentração foi ajustada para $10^{6}$ esporos $/ \mathrm{ml}$.

Após secos, metade dos frutos foram furados em quatro pontos eqüidistantes, na região equatorial, com auxílio de estilete de 1 $\mathrm{mm}$ de diâmetro por $3 \mathrm{~mm}$ de comprimento e sem ponta. A inoculação nos quatro pontos de cada fruto foi realizada logo após a perfuração. $\mathrm{Na}$ outra metade, os frutos foram apenas inoculados nos mesmos pontos, porém sem ferimentos. As inoculações foram feitas em 23/04/2002 com auxílio de um pequeno pincel de pelo de camelo, mergulhando-o na solução de inóculo e, em seguida, aplicando na superfície a ser inoculada. Os frutos inoculados foram acondicionados em sacos plásticos, previamente umedecidos e transferidos para incubadora com temperatura de $25^{\circ} \mathrm{C}$ e fotoperíodo de 12 horas.
As avaliações foram feitas aos 6, 10, 14 e 17 dias após a inoculação. Foram avaliadas as seguintes variáveis: a) percentagem de pontos inoculados, com e sem ferimento, que desenvolveram lesões da doença; b) diâmetro de todas as lesões onde houve desenvolvimento da doença; c) percentagem de lesões com mais de $25 \mathrm{~mm}$ de diâmetro na presença de ferimentos. As avaliações foram feitas contando-se os pontos inoculados que desenvolveram sintomas e medindo-se, com auxílio de paquímetro, o diâmetro das lesões de podridão amarga.

As variáveis diâmetro médio de lesões e percentagem de pontos inoculados com podridão amarga que resultaram em lesões maiores que $25 \mathrm{~mm}$ de diâmetro foram submetidas à análise da variância para o modelo inteiramente ao acaso e as médias de tratamentos comparadas pelo teste de Tukey a $5 \%$ de probabilidade. Para a variável percentagem de pontos inoculados que resultaram em lesão, foi aplicada estatística não paramétrica (teste de Kruskal Wallis) que classifica as médias de tratamentos em pontos.

\section{RESULTADOS E DISCUSSÃO}

A presença de ferimentos nos frutos parece ser fator essencial para o estabelecimento da doença. Segundo Camilo (1989), o método de inoculação em frutos sem ferimentos parece ser menos eficiente e menos consistente do que o método de inoculação via ferimentos. Aos 10 dias após a inoculação, as percentagens de pontos inoculados através de ferimentos que desenvolveram a doença variaram desde $72 \%$ na seleção M-6/00 até $100 \%$ nas cultivares Imperatriz, Golden Delicious, Gala, Baronesa e na seleção M-11/00 (Tabela 1). Na ausência de ferimentos, aos 10 dias a percentagem máxima obtida foi de apenas $8,3 \%$ na 'Golden Delicious', sendo que, em muitos genótipos não havia desenvolvimento de lesões.

Aos 17 dias após a inoculação, a média de pontos inoculados via ferimentos que resultaram em sintomas típicos de podridão amarga ultrapassou $98 \%$, enquanto que apenas $8,6 \%$ dos pontos sem ferimento desenvolveram lesões, confirmando os resultados obtidos por Camilo (1989). Os resultados mostram um gradiente de desenvolvimento da podridão amarga entre os genótipos testados. Este gradiente de reação demonstra a existência de variação no grau de resistência genética entre os diferentes genótipos estudados. As cultivares Condessa, Golden Delicious, Gala e Fuji revelaram-se suscetíveis e a cv. Melrose apresentou nível intermediário de resistência, confirmando os resultados obtidos por aquele autor. As novas cultivares Condessa e Imperatriz, descendentes da Gala, e Baronesa, descendente da Fuji, mostraram alto grau de susceptibilidade, principalmente na presença de ferimentos

TABELA 1 - Percentagem dos pontos inoculados com G. cingulata que desenvolveram sintomas da podridão amarga em frutos de diferentes genótipos de macieira, com e sem ferimentos, no período de 10 a 17 dias após a inoculação.

\begin{tabular}{|c|c|c|c|c|}
\hline \multirow{3}{*}{ Genótipo } & \multicolumn{4}{|c|}{ Percentagem de pontos inoculados que desenvolveram lesão da doença } \\
\hline & \multicolumn{2}{|c|}{ Inoculação com ferimento } & \multicolumn{2}{|c|}{ Inoculação sem ferimento $^{1 /}$} \\
\hline & 10 dias $^{2 /}$ & 17 dias $^{\text {ns }}$ & 10 dias $^{\text {ns }}$ & 17 dias $^{\text {ns }}$ \\
\hline Condessa & $100^{(1)}$ & 100 & 1,7 & 15,0 \\
\hline Gala & $100^{(1)}$ & 100 & 0,0 & 6,7 \\
\hline Imperatriz & $100^{(1)}$ & 100 & 3,3 & 6,7 \\
\hline Baronesa & $100^{(1)}$ & 100 & 0,0 & 8,3 \\
\hline Golden Delicious & $100^{(\mathbf{1})}$ & 100 & 8,3 & 11,7 \\
\hline M-11/00 & $100^{(1)}$ & 100 & 0,0 & 5,0 \\
\hline Daiane & $98^{(2)}$ & 100 & 0,0 & 3,3 \\
\hline Fuji & $98^{(2)}$ & 100 & 0,0 & 13,3 \\
\hline $\mathrm{M}-12 / 00$ & $97^{(3)}$ & 100 & 1,7 & 8,3 \\
\hline Melrose & $87^{(4)}$ & 98 & 1,7 & 3,3 \\
\hline $\mathrm{M}-13 / 00$ & $88^{(4)}$ & 97 & 0,0 & 13,3 \\
\hline Fred Hough & $85^{(5)}$ & 100 & 0,0 & 8,3 \\
\hline M-6/00 & $72^{(6)}$ & 85 & 0,0 & 8,3 \\
\hline Médias & 94,1 & 98,6 & 1,3 & 8,6 \\
\hline
\end{tabular}

"Avaliações feitas considerando apenas os pontos previamente marcados e inoculados em cada fruto

2/ "Rankeamento" pelo teste de Kruskal Wallis, significativo ao nível de $1 \%$ de probabilidade

ns = não significativo 
TABELA 2 - Diâmetro de lesões de podridão amarga $(\mathrm{mm})$ aos 6 e aos 17 dias após a inoculação através de ferimentos e aumento das lesões no período $(\mathrm{mm})$ em diferentes genótipos de macieira.

\begin{tabular}{|c|c|c|c|}
\hline \multirow[t]{2}{*}{ Genótipo } & \multicolumn{2}{|c|}{ Diâmetro lesão $(\mathrm{mm}) /$ dias após inoculação ${ }^{1 /}$} & \multirow{2}{*}{$\begin{array}{c}\text { Aumento lesões } \\
\text { no período }(\mathrm{mm})\end{array}$} \\
\hline & $6 \operatorname{dias}^{2 /}$ & 17 dias $^{2 /}$ & \\
\hline Imperatriz & $11,5 \mathbf{a}$ & $499,4 \mathbf{a}$ & 37,9 \\
\hline Gala & $11,2 \mathbf{a}$ & $46,2 \mathbf{a b}$ & 35,0 \\
\hline Condessa & $11,1 \mathbf{a}$ & 44,0 abc & 32,9 \\
\hline M-11/00 & $10,2 \mathbf{a b}$ & 43,2 abc & 33,0 \\
\hline Golden Delicious & $9,8 \mathbf{a b}$ & 37,5 bed & 27,7 \\
\hline Baronesa & $9,7 \mathbf{a b}$ & 34,8 cd & 25,1 \\
\hline Melrose & 9,4 abc & $32,6 \mathbf{d}$ & 23,2 \\
\hline Fuji & 9,0 bcd & $32,6 \mathbf{d}$ & 23,6 \\
\hline Fred Hough & 8,6 bcd & $32,1 \mathbf{d}$ & 23,5 \\
\hline $\mathrm{M}-12 / 00$ & 8,6 bcd & 36,6 bcd & 28,0 \\
\hline Daiane & 8,4 bcd & 36,6 bcd & 28,2 \\
\hline M-6/00 & 7,2 cd & $27,2 \mathbf{d}$ & 20,0 \\
\hline $\mathrm{M}-13 / 00$ & $7,0 \mathbf{d}$ & $29,3 \mathbf{d}$ & 22,3 \\
\hline
\end{tabular}

1/ Inoculação feita em 23 de abril de 2002.

${ }^{2 /}$ Valores seguidos pela mesma letra na coluna não diferem entre si pelo teste Tukey a 5\% de probabilidade.

TABELA 3 - Percentagem de pontos inoculados com podridão amarga que resultaram em lesões maiores do que 25 mm de diâmetro, dos 10 aos 17 dias após a inoculação em diferentes genótipos de macieira, via ferimentos

\begin{tabular}{|c|c|c|c|}
\hline \multirow[t]{2}{*}{ Genótipo } & \multicolumn{3}{|c|}{$\begin{array}{c}\text { Percentagem de pontos inoculados, com lesão maior do que } 25 \mathrm{~mm} \text { de diâmetro / } \\
\text { dias após a inoculação }\end{array}$} \\
\hline & $10 \operatorname{dias}^{3 /}$ & $14 \operatorname{dias}^{2 /}$ & $17 \operatorname{dias}^{2 /}$ \\
\hline M-6/00 & $0^{3 /}$ & 33,0 cd & $66,2 \mathbf{b}$ \\
\hline M-13/00 & $0^{3 /}$ & $26,7 \mathbf{d}$ & $75,0 \mathbf{a b}$ \\
\hline Fuji & $13,3 \mathbf{b}$ & 45,0 cd & $75,0 \mathbf{a b}$ \\
\hline Fred Hough & $3,3 \mathbf{b}$ & 45,0 cd & $78,3 \mathbf{a b}$ \\
\hline Melrose & $3,3 \mathbf{b}$ & $41,6 \mathbf{c d}$ & 82,1 ab \\
\hline Daiane & $8,3 \mathbf{b}$ & 56,7 bcd & $85,4 \mathbf{a b}$ \\
\hline $\mathrm{M}-12 / 00$ & $1,7 \mathbf{b}$ & 75,0 abc & $85,4 \mathbf{a b}$ \\
\hline Baronesa & $8,3 \mathbf{b}$ & 53,3 bcd & $91,1 \mathbf{a b}$ \\
\hline Golden Delicious & $10,0 \mathbf{b}$ & 73,2 abc & $94,4 \mathbf{a b}$ \\
\hline M-11/00 & $30,0 \mathbf{a b}$ & $91,7 \mathbf{a b}$ & 97,5 a \\
\hline Condessa & $20,0 \mathbf{a b}$ & $93,3 \mathbf{a b}$ & $100,0 \mathbf{a}$ \\
\hline Gala & $46,7 \mathbf{a}$ & $96,7 \mathbf{a}$ & $100,0 \mathbf{a}$ \\
\hline Imperatriz & $51,7 \mathbf{a}$ & $100,0 \mathbf{a}$ & $100,0 \mathbf{a}$ \\
\hline
\end{tabular}

${ }^{1 /} \mathrm{Na}$ avaliação realizada aos 6 dias após a inoculação, não se verificou lesões com mais de $25 \mathrm{~mm}$ de diâmetro

${ }^{2 /}$ Valores seguidos pela mesma letra na coluna não diferem entre si pelo teste Tukey a $5 \%$ de probabilidade

${ }^{3 /}$ Genótipos com média nula não foram incluídos na análise da variância.

(Tabela 1).

Embora os dados da Tabela 1 mostram não existir alta resistência a G. cingulata entre os genótipos estudados, observou-se que, mesmo em genótipos procedentes de parentais suscetíveis, é possível selecionar materiais com bom nível de resistência. Na presença de ferimentos, os menores índices de desenvolvimento de lesões de podridão amarga foram obtidos com as seleções M-6/00 e M-13/00, descendentes diretas da Imperatriz e da Fred Hough, cultivares que se mostraram susceptíveis neste estudo (Tabela 1).

A seleção M-13/00 mostrou percentagem relativamente alta de lesões na ausência de ferimentos. No entanto, as lesões evoluíram mais lentamente do que nas cultivares Imperatriz, Gala e Condessa (Tabela 2).

Na presença de ferimentos, a reação de resistência da seleção M-6/00 evidenciou-se pela menor percentagem de pontos inoculados que resultaram em lesões da doença (Tabela.1) e pelo menor tamanho das lesões, comparativamente às cultivares Imperatriz, Condessa e Gala (Tabelas 2 e 3). Aos 6 dias após a inoculação, a seleção M-13/00 desenvolveu lesões significativamente menores do que as da cv. Melrose, constatada como resistente por Camilo (1989).

Segundo Camilo (1989), a progressão e o tamanho final das lesões de podridão amarga parecem expressar melhor a resistência relativa entre diferentes genótipos de macieira, em relação a outras variáveis. As cultivares Imperatriz, Gala, Condessa e Golden Delicious e a seleção M-11/00, não só foram as que tiveram as maiores percentagens de ferimentos inoculados que resultaram em lesão, mas também foram as que tiveram a progressão mais rápida da doença, com as maiores percentagens de lesões com diâmetro acima de $25 \mathrm{~mm}$ a partir do $10^{\circ}$ dia da inoculação (Tabela 3). Aos 14 dias após a inoculação, nestes genótipos já havia mais de $91 \%$ das lesões com mais de $25 \mathrm{~mm}$ de diâmetro. No outro extremo, as seleções M-6/00 e M-13/00, nas quais não havia lesões acima de $25 \mathrm{~mm}$ de diâmetro aos 10 dias após a inoculação, aos 14 dias apenas $33 \%$ e $26,7 \%$ das lesões haviam crescido mais de $25 \mathrm{~mm}$, respectivamente. Na cultivar Melrose houve progressão intermediária da doença, mostrando possuir grau intermediário de resistência.

A baixa incidência de lesões de podridão amarga na ausência de ferimentos é um bom indicativo da importância de se manter os frutos bem protegidos do ataque de insetos, notadamente a moscadas-frutas, Anastrepha fraterculus (Wied., 1830). Os resultados obtidos neste estudo indicam que ferimentos provocados na epiderme do fruto facilitam o ingresso, o estabelecimento e o desenvolvimento da podridão amarga em maçãs.

\section{CONCLUSÕES}

Os resultados obtidos no presente estudo permitiram as seguintes conclusões: 
1) G. cingulata se estabelece mais rapidamente em frutos com ferimentos do que em frutos sem ferimentos.

2) Para estudos de resistência genética à podridão amarga em maçãs, o estabelecimento da doença na presença de ferimentos é muito mais rápido do que em frutos sem ferimentos, indicando que o emprego deste método em trabalhos de melhoramento genético pode resultar na eliminação de materiais que, na ausência de ferimentos, poderiam expressar bom nível de resistência.

3) Existe segregação genética para resistência a G. cingulata em macieira, possibilitando o desenvolvimento de novas cultivares resistentes, mesmo a partir de cruzamentos entre algumas das atuais cultivares tidas como suscetíveis.

\section{REFERÊNCIAS BIBLIOGRÁFICAS}

ANDERSON, H.W. Diseases of Illinois. Urbana: Agricultural Experiment Station, University of Illinois, 1920. p. 26-31. (Circular, 241).

BLEICHER, J. Fatores predisponentes para a ocorrência da podridão amarga, Glomerella cingulata, em maçã. Florianópolis, Empresa Catarinense de Pesquisa Agropecuária, 1980. 17p. (Comunicado Técnico, 36).

BLEICHER, J.; MELZER, R.; BERTON, O.; BONETI, J.I.S.; DRIESSEN, A.C. Doenças da macieira. In: EMPRESA CATARINENSE DE PESQUISA AGROPECUÁRIA. Manual da cultura da macieira.
Florianópolis, 1986. 562p. ilust.

BONETI, J.I.S.; RIBEIRO, L.G.; KATSURAYAMA, Y. Manual de identificação de doenças e pragas da macieira. Florianópolis: Epagri, 1999. 149p.

CAMILO, A.P. Genetic resistance in Malus to Glomerella cingulata (Stoneman) Spaulding \& Von Schrenk: Sorces of resistance, leaf infection, progeny evaluation, and pathogenecity. 1989. 116f. Tese, Cornell University, Ithaca, 1989.

CLINTON, G.P. Apple rots in Illinois. Urbana: Agricultural Experiment Station, University of Illinois, 1902. p.193-224. (Bulletin, 69).

DUNEGAN, J.C. Bitter rot of apples. In: PLANT DISEASES. U.S. Dep. Agric. Yearbook, 1953. 940p.

KAUL, J.L.; MUNJAL, R.L. Mode of entry, post infection, and histopothological changes in apple fruits due to rot causing fungal pathogens. Gartenbauwissenschaft, Stuttgart, v. 46, p. 55-58, 1981.

ROBERTS, J.W.; PIERCE, L. Apple bitter rot and its control. U.S. Dep. Agric., 1918. 10p. (Bulletin, 684).4

SCHRENK, H.; SPAULDING, P. The bitter rot of apples. U.S. Dep. Agric. Bur. Plant Ind, 1903. 54p. (Bulletin, 44).

SINGH, B.M.; CHAND, J.L. Studies of the resistance of apple fruits to bitter rot caused by Gloeosporioides fructigenum, Berk. II.Analysis of amino acids, organic acids, and carbohydrates. Indian Journal of Microbiology, Ashford, v.9, p. 78-83, 1969. 